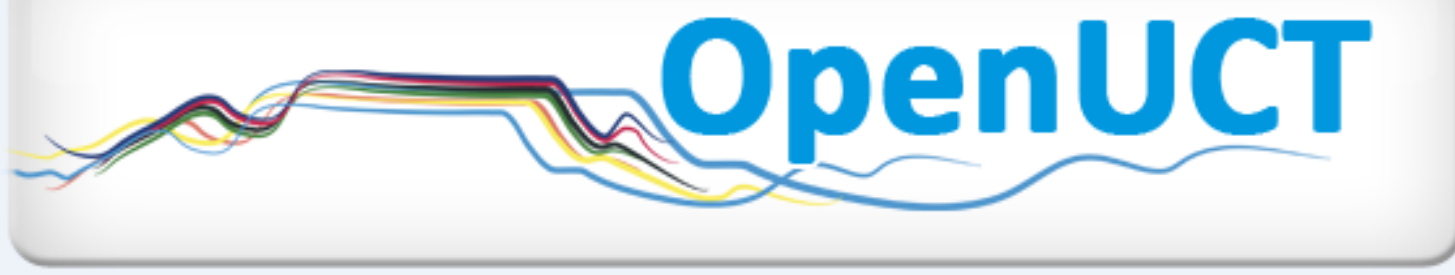

This is the author-approved manuscript version of a journal article published in:

Archer A. 2006. Opening up spaces through symbolic objects: harnessing students' resources in developing academic literacy practices in engineering. English Studies in Africa. 49(1): 189-206. DOI: 10.1080/00138390608691349.

It is made available under the terms of agreement between the author and the journal, and in accordance with the University of Cape Town's Open Access Policy for the purposes of research, teaching and private study.

http://www.openuct.uct.ac.za/sites/default/files/UCTOpenAccessPolicy.pdf 


\title{
OPENING UP SPACES THROUGH SYMBOLIC OBJECTS: HARNESSING STUDENTS' RESOURCES IN DEVELOPING ACADEMIC LITERACY PRACTICES IN ENGINEERING
}

\author{
Arlene Archer \\ Writing Centre, University of Cape Town. \\ Arlene.Archer@uct.ac.za.
}

\footnotetext{
-his article reports on one aspect of my $\mathrm{PhD}$ study, which I undertook as a teacher-researcher in the context of a first year Communication Course in a South African engineering foundation programme. The programme caters for students from less advantaged educational backgrounds and the course focuses on developing students' academic literacy in English. I argue that less regulated spaces need to be created in the curriculum in order to allow student resources to emerge and to be validated. These resources include English, indigenous languages, local knowledges, personal experience and multimodal competencies. By less regulated spaces, I mean classroom environments which require open tasks with no strict generic guidelines specified. Also, classroom environments which place less emphasis on assessment and more emphasis on creativity, and the use of students' own resources. I analyse the texts the students produce in one of these less regulated spaces in order to identify and describe the discourses that they draw on and propagate. Once visible, these discourses become resources for both teacher and students to draw on. I attempt to suspend 'teacherly' judgement, put learning and the formal curriculum aside and look at students' texts free of a norm-driven, evaluative eye in order to see the ways in which traces of their lives manifest.

In South Africa resources like local languages and certain kinds of indigenous knowledge tended to be under-valued in the previous political dispensation. There was a general ethos of boundary-making with an attempt
} 
to police a multitude of these boundaries. Currently we are in a period of flux and transition where boundaries between practices are being debated, as are boundaries between academic disciplines and domains of knowledge. This loosening up of academic boundaries is a global phenomenon. According to Luke:

\footnotetext{
Disciplinary and institutional boundaries between science and humanities, between the 'hard' natural sciences and 'soft' human sciences, between the public discourses of science and domains of folk wisdom have become the focus of unprecedented scrutiny. (Luke in Halliday and Martin xi)
}

Perhaps the kind of unstructured curriculum spaces I am advocating here tend to happen more organically in a Humanities environment where students are encouraged to reflect on both their personal and societal practices. But, what are the benefits of using less regulated curriculum spaces and multimodality in developing literacy practices in a non-Humanities environment? Studies that explore the benefits of opening up teaching practice through multimodality have largely been conducted in the domain of Humanities (Kress; Kress and Jewitt; Gee; Pahl), although science education (Kress, Ogborn, Jewitt and Tsatsarelis) has also featured. However, to date, there have not been many studies showing the benefits of a multimodal epistemology in opening up meaning-making at the higher education level broadly and in professional degrees like Engineering specifically.

In traditional first year Engineering courses, knowledge tends to be atomized into subjects like Maths and Physics which are not always related directly to the 'real world'. In this context, a curriculum which validates and uses students' resources and discourses is invaluable, as students interrogate their past situations and their future aspirations. They also start to think critically of Engineering as a profession within the context of South Africa. This kind of curriculum coheres with a general international shift in the professional disciplines towards the subjective, the affective and more 'Humanities' type concerns. There is a trend to create a balance between technical and non-technical aspects in Engineering curricula designs (Wulf; Horack). Evident in this trend is the acknowledgement that engineering is a social activity with political, ethical and economic dimensions. I argue for exploring these new curriculum spaces and new multimodal approaches to developing academic literacy practices in Engineering. 


\section{DEVELOPINGACADEMIC LITERACY PRACTICES IN ENGLISH THROUGH MULTIMODAL PEDAGOGY}

Less regulated curriculum spaces are able to draw on and experiment with a range of genres and modes in a way that is not always possible in highly regulated genres such as the written report. By 'mode' I mean the culturally shaped material available for representation, such as the visual, written or oral mode. Since the mid-90s, Kress and Van Leeuwen, Kress, Stein, the New London Group and others have pointed out that there has been a semiotic shift from the verbal to the visual, resulting in an increasing multiplicity and integration of modes of meaning-making. The implication of this shift for Higher Education is that the increasing variety of multimodal text forms needs to be reflected and recognized in the curriculum. Producing text in the written mode can be a major stumbling block for students in South Africa who have to write in a language that is not their own and have to adopt discipline-specific discourses and genres. A multimodal pedagogy seeks to go beyond written and spoken language to value a range of modes through multimodal assessment practices. One could argue, as a number of theorists have done, that a multimodal pedagogy is necessary to address equity and access issues. Stein argues that multimodal approaches are theoretically more equitable than monomodal pedagogies (Stein 333). On the other hand, Thesen acknowledges that multimodal texts in the curriculum raise new questions about power and access, but may not necessarily open up access routes in a word-based field such as Humanities (Thesen 132).

I do not advocate a multimodal approach as an alternative way of inducting students into academic literacy practices in English, nor as a step on the way to improved writing practices. Rather, I am interested in how students express interest through available resources, what resources students bring to academic and disciplinary genres and the ways in which this 'cultural capital' (Bourdieu) can be incorporated into the curriculum. Kress talks about text production as based on the interested action of 'socially located, culturally and historically formed individuals, as the remakers, the transformers, and the re-shapers of the representational resources available to them' (Kress 155). This view recognizes that meaning-making is about choosing and assembling resources in relation to individual desire as well as perceptions of audience and context. In the act of making meaning 'learners produce multiple signs in textual forms across semiotic modes, drawing on different representational resources in order to succeed in that domain' (Stein 333). This view of the sign-maker emphasizes students' motivations for the uses of 
particular forms, rather than on incompetence and deficiency. This is important in looking at students' texts.

\section{HARNESSING STUDENTS' RESOURCES THROUGH SYMBOLIC OBJECTS}

The site for this study is a Communication Course in an Engineering foundation programme which caters for students from academically underprepared backgrounds. The students are diverse in terms of languages, home countries, age differences, rural and urban origins and gender. For most English is an additional language and the Communication Course concentrates on developing students' academic literacy in English.

One of the less regulated curriculum spaces on the course is the Symbolic Object project. Students identify everyday objects that have symbolic meanings and investigate these objects in a range of contexts. For instance, someone may choose to have a microwave or electric kettle in a place that has no electricity. Here the object has little 'functional' use, but has symbolic value, such as aspirational value. In this context, objects are seen as catalysts for enabling student narratives and understandings to emerge. Students produce a text in any medium which discusses the physical characteristics and uses of the object, as well as the symbolic, social and cultural meanings people attach to it. They are able to choose between predominantly written modes or predominantly visual modes (such as posters, photos or video). They write a brief justification for their choice of mode of production and think about the relevance of the project for themselves as future engineers. The aim of the project is to explore ways in which particular communities of practice make meaning and the possible implications of this for 'development' work. Although the parameters of the task were very broad, the projects were assessed according to the following criteria: the exploration of the physical, cultural and communicational understandings of the object; the quality of research, interviews and observations; the appropriateness of the choice of mode of presentation and the students' reflections on their choices. This emphasis on student reflection was an attempt to counteract the technocist tendency in assessment practices and to see the Symbolic Object texts as process, rather than product.

Some of the objects that the students identified include technological 'objects' (such as electricity and cars), natural objects (flowers, trees, doves and lions), bodily adornments, including clothes (short skirts, designer labels, pants and uniforms) and jewellery (rings, chains, beads and goat's hair 
necklace). They also identified objects relating to crime (burglar bars, barbed wire and guns), political objects (flags and statues), objects representing illness (AIDS ribbon and TB symbol), religious objects (bible, cross, moon and star, rosary and dreadlocks). In this article, I look at the text produced by one group of students which examines the 'flower' as their object.

\section{DRAWING ON STUDENTS' LIFEWOFUDS: HOW MTHOKO FROM NOBODY INTRODUCED FLOWERS INTO ENGINEERING}

The group of students that focused on flowers as symbolic objects comprised Thabang, Mthoko and Mbongiseni. One student in the group, Mthoko, was rather a fringe character in the class. He was a devout Rastafarian who read his bible up to four times a day. He came from a rural area in the Limpopo Province which has the rather otherworldly name of 'Nobody Village', and he embraced this rural 'traditional' identity. The Symbolic Object project seemed to have found resonances with him. He commented in class that this was 'just his type of thing' because everyday objects signify many things to him. For instance, the green hat that he wore meant something to him. He explained this by saying that in the Rasta community the month in which you were born has a colour associated with it; in his case he was born in January and the associated colour is green. He clearly enjoyed sharing the symbols of the Rasta culture with the rest of the group and the others expressed interest in what he had to say.

The text that these students produced looks at the physical and symbolic meanings of flowers (see Figure I). The reason 1 chose the Flowers poster for this analysis is that it reveals an interesting perspective on nature. Nature and society are seen as inextricably linked and the spiritual and the physical are given equal status. Nature is portrayed as an agent providing portents and signs to humans (for example, blossoms indicate conception). This is in contrast to a perspective where nature is portrayed as passive, as serving the needs of humans, as something to be 'harnessed', which is prevalent in some views of development and engineering. The underlying idea here is that a 'developed' state can be achieved through creating boundaries between humans and nature. In order to understand what sustainable development could possibly mean in a country like South Africa, these views of nature and the relations between the social and the natural need to be explored with students.

The Flowers poster provides a definition of flowers, describes their function for plants and discusses humans' physical interaction with them, in the form of gardening, decoration and medicinal uses. It describes different 


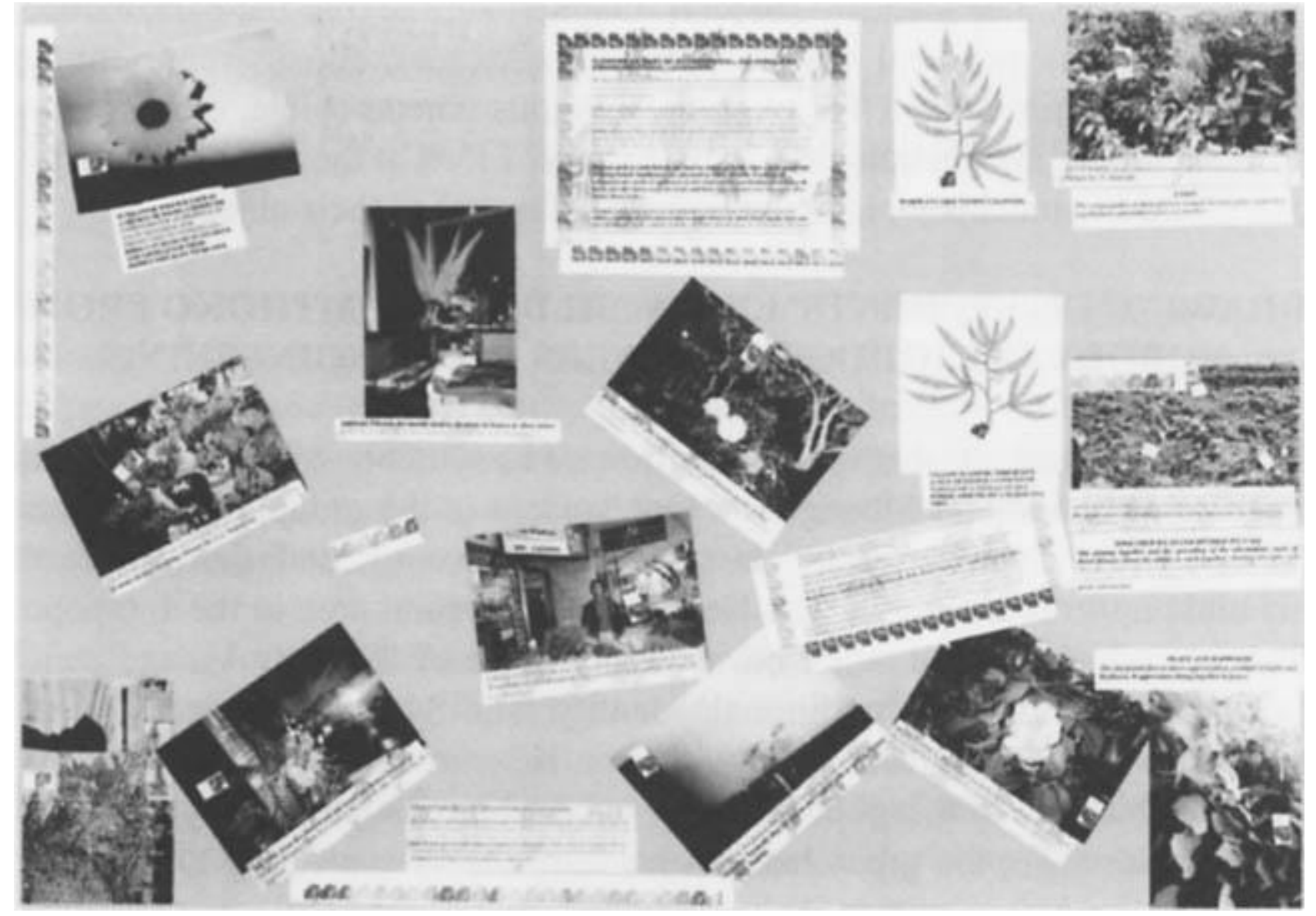

Figure 1. Flowers poster

social meanings of flowers, as both gifts and commodities, as well as cultural meanings, where flowers can indicate love, peace, happiness and life. This is how Thabang describes different meanings of flowers:

When coming to cultures, flowers are observed differently and this leads to different beliefs. Most people believe that red roses are the symbol of love whereas rastafarians believe that they show the shed blood of their heroes ... flowers are believed to convey certain messages to certain people depending on their appearance, colour and quality sometimes. This goes to an extent where flowers are given the meanings relative to their appearance. (Thabang's written reflection on the project)

Colour is a source of pleasure and affective meaning in the Flowers poster. Bright yellows, reds and greens dominate, making this poster colourful and attractive to the eye. The materiality of the mode (the glossy sheen of the photographs) also contributes to the brightness of the representation. The attempt to design an aesthetically appealing text is in keeping with the emphasis in the poster on the beauty of flowers and the positive, life-affirming nature attributed to them. The writing is printed over a faint leaf design, which 
turns the written text into an occasion for visual display. The students have used a repetition of a visual motif, a thumbnail size picture of a rose as a connective element.

\section{TRANSLATINGBETWEEN DOMAN3 OF PRACTICE}

There is no formula for passing from one to another of the provinces within our life worlds. Schutz stresses that the translations between these provinces are always experienced as more or less of a shock because each province tends to have its particular concerns, activities and semiotics. In the tertiary context, students need to make translations between various domains of practice and their habitualized forms of representational practice. Schutz refers to a 'stock of knowledge' which includes 'the set of practical recipes for attaining typical ends by typical means - recipes which have 'stood the test' thus far and are therefore taken for granted' $(72-73)$. The ways in which these 'recipes' or habitual ways of thinking and acting are drawn on in the curriculum has implications for knowledge production. For instance, the Flowers poster draws on scientific textbook conventions, 'recipes' from the school context. The use of typographical features such as bold print, bullet points and italics to highlight key points draws on these conventions. The 'before' and 'after' representation of the marijuana plant has provenance in textbook genres, as does the language of school Biology ('the spreading of the adventitious roots'). These examples indicate that students' resources include experiential knowledge, as well as school-based knowledge.

The students are aware of the constraints on representation which they perceive to be attendant on a task of this nature within a pedagogical domain of practice. For instance, the word 'dagga' which has common currency in South Africa is not used on the Flowers poster. Rather the word 'marijuana' is used which has cultural provenance and aligns the group with global Rastafarian culture rather than other South African subcultures. Marijuana is also the official word which students may have deemed more appropriate for an assessable curriculum task. Whatever the reason, it is clear that the choice of lexis is based on student interest, whether conscious or unconscious.

The Symbolic Object project serves to raise awareness of the socially constructed nature of practices. Although cultural practices may appear constant, timeless and static, they are in fact a constant re-enactment, a reactualization in daily practice. 'Ordinary culture hides a fundamental diversity of situations, interests, and contexts under the apparent repetition of objects that it uses' (De Certeau 256). The Flowers group talked of the construction of meaning, and culture propagating itself: 'a certain society 
believed that if you give bright natural flowers to someone who is sick, he would recover. Automatically, this goes around from generation to generation and becomes an instinct of that culture, society, religion etc.' (Flowers poster). This statement highlights that meanings are created to become the norm; they are not natural or given. The students mentioned the importance of the project in alerting them to different practices and beliefs across communities, and emphasized the importance of this in development work:

I think one day I will be involved in a development project and will have to work with the community. I think to foster good communication I would have to have a perception of what the values of the people in community are. I have to have a grip of what is culturally unacceptable in that particular community to ensure that what I propose does not offend them. (Mbongiseni's written reflection)

This reflection shows how students are grappling with both their own experiences of reality and the realities of others in South Africa.

\section{ACKNOWLEDGING STUDENTS' DISCOURSES}

The Symbolic Object project allows students to experiment with diverse resources in an informal and unstructured curriculum space and allows them to draw on different kinds of knowledge and competencies, including experiential knowledge and students' primary and secondary discourses. According to Gee, primary discourses are those which people acquire early in life within the socio-cultural setting of the family. Secondary discourses are those that have to be learnt as part of socialization within local and national groups outside of early home socialization (137). One of the aims of the Symbolic Object project was to give students a chance to draw on the discourses arising out of their life worlds.

Because the project takes place at the beginning of the year and within a less regulated curriculum space, it is well-positioned to identify students' resources before these become negotiated with the expectations of the academy and the discourse of Engineering. I put learning and the formal curriculum aside in order to do textual analysis, and look at how particular discourses are realized in students' texts. The understanding of discourse that I work with is that developed within recent social theory, based on the work of Foucault, to refer to the ways social institutions define and regulate the practices within those institutions. In other words, discourses are 'socially constructed knowledges of (some aspect of) reality which give expression 
to the meaning and values of an institution or social grouping' (Kress and Van Leeuwen 4). I now look closely at two discourses which emerge strongly in the Flowers poster, namely religious discourse and utopianism. These discourses are especially interesting in a country in transition like South Africa. Both are idealistic and aspirational, and construct nature and society in a particular way. These are secondary discourses from a non-academic context and it could be useful to bring these into more explicit dialogue with the discursive conventions of the engineering discipline.

\section{RELIGIOUS DISCOURSE: CONFLATION OF THE MATERIALAND THE SYMBOLIC}

Religious discourse propagates a set of values and principles and is realized through particular genres with specific rhetorical and lexicogrammatical conventions. A Rastafarian discourse is evident in the Flowers poster in the use of rather archaic biblical lexis and grammatical constructions: 'a conceived woman', 'congregation of flowers' and 'shed blood'. In the written text, a Rastafarian discourse is explicitly evoked in statements such as 'Rastafarians claim this to be true' and 'Rastafariansuse red flowers to simplify [signify] shed blood of their heroes'. There is slippage between being immersed in the Rastafarian life world and framing that life world and its participants from the outside: 'they believe' and 'they are periodically living in this situation'. This framing could be about educating non-Rastafarians and thus does not assume insider status. In the images, Rastafarian discourse is presented as 'natural' and is positioned as non-relative meaning. For instance, the 'before' and 'after' structure of the diagram of the marijuana plant locates it within a scientific discourse, where the focus is on the production of blossoms. The caption below the diagram, however, locates the meaning as cultural and spiritual: 'Yellow flowers, which give a sign of either a conceived woman or a woman on her period'. It seems that, compared to Western society and its discursive organization, Rastafarian society tends to conflate the discourses of science and mysticism, the material and the spiritual. Mystical knowledge is one way of constructing relations between elements in the natural world, and comprises a different form of reasoning to scientific knowledge in a Western empiricist tradition. Science is both a method of empirical investigation of knowledge, and what has been canonized and naturalized as 'truth'. This way of viewing the natural world in Western empiricist traditions is in sharp contrast to practices labelled as shamanism or magic, where the symbolic, cultural and physical are less overtly separated. 


\section{UTOPIANISM: THE 'RAINBOW NATION’}

The discourse of utopianism constructs and narrativizes the future. By promoting an imagined ideal state, this discourse can either be about 'change' or about 'conservation'. The imagined ideal state is defined according to the meanings and values of a particular institution or social grouping. Utopian discourse in the Flowers poster draws on an over-simplified notion of 'rainbow nationalism' employed by the new South African nation to highlight and celebrate diversity, which sometimes masks complex and contradictory configurations of identity. This view of the 'rainbow nation' is achieved predominantly through personifying flowers, or at least giving them agency, as in statements such as 'Peace and Happiness. The outgrown flower shows appreciation, youthful delights and liveliness. It appreciates living together in peace'. Here human emotions and perceptions are attributed to the flowers. The utopian discourse of peace, harmony and unity in the poster coheres with the Rastafarian discourse outlined above. One of the captions reads: 'Unity. The congregation of these flowers around the same place symbolises togetherness and patience for one another'. 'Congregation' has religious connotations: the gathering of people for a religious meeting. There are clearly strong links and overlaps between religious and utopian discourses and both tend to be aspirational in their constructions of nature and society.

\section{STUDENTS' RECONTEXTUALIZATION OF THEIR DISCOURSES}

In the less regulated context of the Symbolic Object project, the students were able to draw on the primary discourses of religion and utopianism in order to reflect on the academic context and the Engineering profession. According to Bernstein, when a discourse moves, through recontextualising, from its original site to a pedagogic site the original discourse is abstracted from its social base, position and power relations (53). This notion of 'recontextualization' is useful in thinking about the ways in which students recontextualize discourses in the pedagogic setting.

The Flowers group invented an adjective which they used on the poster to describe someone with the attributes of flowers, namely 'flowerish'. The 'flowerish' discourse created by the students is an interesting example of recontextualization. Flowers are used to carry the religious and utopian discourses of the students, as well as the environmental and political discourses of the course: 
As flowers reflect good communication skills such as showing love to someone practically by giving him flower, working together as a team of different people of different national groups, sharing property like different flowers share a particular part of fertile soil to grow, this is all what engineer does. (Mbongiseni's written reflection)

Here Mbongiseni sets up an analogy between the way flowers 'share a particular part of fertile soil' and the sharing and team work necessary in Engineering practice. In Mthoko's written reflection on the project, he attempted to link the notion of team work and unity with the context of the course, namely 'development':

This project is ... relevant to me as an Engineer because in Engineering there is lot of destruction, which may lead to destroy some important things such as flowers. Since I know the importance of flowers in some contexts, I will know what to do if I have to work in that context. It is either I stop destruction which may destroy or I change a plan of my work. (Mthoko's written reflection)

Here Mthoko equates flowers with nature as well as with something fragile. He maintains that insensitive development, or development without careful thought, could lead to the 'destruction' of nature or other fragile entities. The extended metaphor of 'flowers' is used as a basis for a metalanguage to comment on aspects other than the course curriculum and Engineering, including political and religious beliefs:

In areas where there are flowers, there is usually not any other species except flowers of different kinds. This encourages people if they can combine together regardless of their colour they can win or beat enemies. As this is shown by flowers when a different species grow between the bunch of them it dies out. In church people used to display this. This is done in an intention to show that if Christians can join together they can beat devil or any evil spirit.

(Mbongiseni's written reflection)

The notion of team work in a professional setting is broadened here to include a kind of religious militancy, an 'us' and 'them' scenario. Unity in spite of diversity is emphasized: people should 'combine together regardless of their 
colour'. However, the new group thus formed is established in opposition to another, the 'enemies'. A similar opposition is set up when the student uses the 'flower' as carrier of political discourse.

I would also go and plant more flowers in Zimbabwe more specifically next to where President Robert Mugabe lives. This can change his attitude and make him realise that we have to join together as people of different colours to win the devil, which is trying, to rule in the country.

(Mbongiseni's written reflection)

Here the 'flower' is not used in the sense of 'peace and love' associated with the hippie movement of the 60s and 70s. Rather, the student builds on his previous idea of creating unity in order to oppose something, in this case 'the devil which is trying to rule'.

According to Bakhtin, 'internally persuasive' discourses are ways of meaning with which the individual has dialogically engaged through questioning and exploration in order to develop a newer way of meaning (Bakhtin 346). This 'persuasive' discourse is interesting in thinking about the ways of talking developed by the Flowers group. Using flowers to talk about concerns in Engineering, like team work and consideration for nature in development, reveals that students are exploring and playing with concepts in order to come up with innovative ways of meaning-making. It is clear that certain kinds of reflection require different kinds of thinking which draw on different lexical and grammatical domains.

\section{WORKING WITH STUDENTS' CONCEPTUAL STRUCTURES: OPENING UP CLASSIFICATION BINARIES}

In an unregulated curriculum space, an environment is created where binaries can be made explicit, opened up and challenged. Generally speaking, the Flowers poster classifies concepts according to a binary logic, into symbolic and scientific meanings. The symbolic meanings include cultural meanings 'shed blood of heroes', religious meanings 'conception' and personal meanings 'teamwork, unity, peace'. The scientific meanings include realms such as food, medicine and economics. In these binaries, there does not seem to be valorization of one pole of the opposition. For instance, the caption beneath the diagram of the marijuana plant which describes beliefs about the plant is written in upper case and the caption beneath the sunflower explaining its commercial and scientific uses is also written in upper case. By using upper case for these two captions, it seems that the symbolic and the functional are 
given equal status, and the explanation based on 'belief' is given equal authority to the 'scientific' explanation of the sunflowers. This is in contrast to Western Anglophone academic discourse where hierarchical binaries are established. Here, the generalizable tends to be valued over the context-specific, academic truth (published research) over personal experience, closing down of possible meanings over open-endedness, certainty over uncertainty. Because binary logic is an integral feature of certain kinds of academic discourse, it is worth alerting students to the ways in which it functions.

An inclusive 'and' logic could be a way of playing with conventions, but it could also be symptomatic of students grappling with systems of classification. At times, the classification binaries in the Flowers poster blur in jarring ways, as in the caption for the photograph of the ivy growing on the campus walls. The university community sees the ivy as signifying an important time of the year - when the ivy turns red it means exam time is near. The caption reads as follows:

Winter Signs. Ivy on the walls of Smuts Hall. It grows on the walls of the buildings and covers them. They do not have big worms like the grape trees which also grow the same way as the ivy.

Here it is important to elucidate the classificatory principles. The symbolic ('Winter signs') and the physical (worms, patterns of growth) are thrown together in this statement, creating a disjuncture in the classification system operating in the poster. Sometimes, however, this mix of discourses and domains of practice is done in a way that does not produce disjuncture in meaning but is, rather, highly evocative and generative. For example, the text block entitled 'Together we stand divided we fall' reads:

The joining together and the spreading of the adventitious roots of these flowers shows the ability to work together, sharing strengths and they also create more security amongst themselves and the surrounding objects also benefit. For instance they also protect the earth surface from soil erosion.

Although the title ('Together we stand divided we fall') frames this as a symbolic orientation overall, there are easy shifts within this from the language of school biology ('the spreading of the adventitious roots') to symbolic orientations ('shows the ability to work together, sharing strengths and they also create more security amongst themselves and the surrounding objects 
also benefit'), to the domain of development explored in the Communication Course ('For instance they also protect the earth surface from soil erosion'). As the above example shows, 'breaking' or reinterpreting some standard generic conventions can often signal an encounter of diverse knowledges and differently organized social worlds.

\section{'NOBODYAND CO’: AUTHORIAL VOICE}

In the less regulated curriculum space of the Symbolic Object project, the students were able to draw on a range of knowledge sources: researched knowledge, 'folk' knowledge, systems of belief and practice, as well as experiential knowledge. Within the Flowers poster there is no indication of the status of knowledge; knowledge from different sources is presented equally factually. The physical properties of the flowers are presented in the same way as the beliefs about flowers and love. A less regulated curriculum space enables this kind of mix of domains of knowledge to emerge.

The students could choose their own objects for investigation and talk about why certain objects were meaningful to them. During the Symbolic Object project, sharing of knowledge and the excitement generated around this sharing was tangible in the classroom. Bringing in different kinds of knowledge from different contexts also changed the power dynamics between the teacher and the students, where the students became the experts. These shifts in power had an impact on authorial voice.

Interestingly, in the Flowers poster, strong authorial voice is maintained, even whilst the relativity of meaning is demonstrated. There are many strong statements of authority, presumably because the students drew on the collective knowledge of the group. The main text block on the poster begins with 'We have two classes of flowers'. This exposition continues with more present tense statements of generalizable truth: 'People use to decorate their yards and houses by flower' and 'Flowers such as cauli-flowers are used as sauces of food'. Alongside the strong statements of generalizable truth, the relative nature of cultural practices is also emphasized with words like 'usually, 'some people', 'mostly', 'sometimes', but not through the use of tentative modals such as 'could'. This lack of tentative modals enables a strong authorial voice to be maintained, whilst still pointing to the relativity of meanings. The awareness of the socially constructed nature of meaning is also demonstrated in the use of the expression 'are believed to': 'pink roses are believed to symbolise love and fond because of their colour and they look innocent'. Here an agreed upon view is aired in the passive form. This social view is thrown together with a personal idiosyncratic view: 'and they 
look innocent'. These distinctions between socially constructed and idiosyncratic views are not indicated on the poster.

\section{FINAL COMMENTS}

In this article, I have argued for the importance of creating less regulated curriculum spaces in Higher Education in order to harness students' multimodal resources. I have described a project that aimed to do this in Engineering and have attempted, through analysing one student text, to demonstrate how students utilize resources. By advocating a curriculum that 'harnesses' students' resources I do not mean simply using these resources, but encouraging students to interrogate them critically. For instance, identifying the underlying classification structure in texts (such as binaries) and looking at how these hnction ideologically. It is important to encourage explicit dialogue between students' resources and the discursive conventions of the Engineering discipline. I have shown how the students already began this dialogue by using religious and utopian discourses to comment on the academic context and the Engineering profession. These metalanguages, grown from the encounter between students' primary discourses, other secondary discourses and academic discourse, need to be made visible in the classroom, interrogated and problematized, and moved to the next 'level', namely the domain of the Engineering discipline. Elsewhere, I have explored how resources from unregulated environments can be utilized in the regulated environments of more mainstream curricula (Archer 2004, 2006). The professional disciplines, including Engineering, are beginning to rethink the varieties of interdisciplinary knowledges and therefore the kinds of texts required in their field. What students need to manage in this environment is modal flexibility: they need to have the competence to move with ease across genres and modes, drawing on the expanded repertoire of resources available to them. To date, non-Humanities courses and professional disciplines such as Engineering have lacked meaningful courses in literacy and language development. That is, courses that demonstrate how much students know about literacy practices, and how they can build on that knowledge.

In the less regulated curriculum space of the Symbolic Object project, students could experiment with multimodal representation and a range of resources whilst acquiring knowledge of both English and academic literacy practices. Different modes can enable different kinds of being and knowing which has particular implications for students who have English as an additional language. For instance, students who struggle with classifications, comparisons and analytical hierarchies in the written modes, could do better 
with conceptual structures in the visual mode. This study demonstrates that students who have traditionally felt lacking in language, specifically English, are in fact carriers of key resources that can inform their reading and writing.

In sum, creating less regulated curriculum spaces opens up opportunities for playfulness, humour and irony, as well as exchange of cultural and personal knowledge across multiple modes. Constructing such a pedagogy of diversity and unity is imperative in the current South African context with state policy that is committed to increased access, social redress and equity in tertiary education.

\section{ACKNOWLEDGEMENTS}

I am grateful to my students in the Communication Course, as well as Lucia Thesen and the anonymous reviewer for their invaluable comments. This material is based upon work supported by the National Research Foundation (Thuthuka) and the University of Cape Town Research Committee. Any opinions, findings or recommendations expressed in this material are those of the authors and therefore the NRF does not accept any liability in regard thereto.

\section{WORKS CITED}

Archer, Arlene. 'Access to Academic Practices in an Engineering Curriculum: Drawing on Students' Representational Resources through a Multimodal Pedagogy'. Unpublished PhD thesis. University of Cape Town, 2004.

. 'A Multimodal Approach to Academic 'Literacies':

Problematizing the Visual/Verbal Divide'. Language and Education 20.6 (2006): 449462.

---------. 'Change as Additive: Harnessing Students' Multimodal Semiotic Resources in an Engineering Curriculum'. Academic Literacies and Languages of Change. Ed. Lucia Thesen and Ermien van Pletzen. London: Continuum, 2006: 224-25 1.

Bakhtin, Mikhail. 'Discourse in the Novel'. The Dialogic Imagination:

Four Essays. Ed. and translator Michael Holquist. Austin:

University of Texas Press, 1981: 259422.

Bernstein, Basil. Pedagogy, Symbolic Control and Identity: Theory,

Research, Critique. London: Taylor and Francis, 1996. 
Bourdieu, Pierre. Language and Symbolic Power. Cambridge, Massachusetts: Harvard University Press, 1991.

De Certeau, Michel, Giard, Luce, Mayol, Pierre. Luce Giard. Translator Timothy Tomasik. The Practice of Everyday Life, Volume 2: Living and Cooking, MinneapolisILondon: University of Minnesota Press, 1998.

Foucault, Michel. 'The Order of Discourse'. Untying the Text: A PostStructuralist Reader. Ed. Robert Young. 1981. BostodLondonl Henly: Routledge and Kegan Paul, 1970: 48-77.

Gee, James. Social Linguistics and Literacies: Ideology in Discourses. Second edition. London: Falmer Press, 1996.

Situated Language and Learning: A Critique of Traditional. Schooling. Oxfordshire and New York: Routledge, 2004.

Halliday, Michael and Martin, Jim. Writing Science: Literacy and Discursive Power. London and Washington, D.C: Falmer Press, 1993.

Horak, Emile. 'A Study of the Thinking Styles and Academic Performance of Civil Engineering Students'. For Engineering Education 7.1 (2003): 4-7,

Kress, Gunther. 'Multimodality'. Multiliteracies. Literacy Learning and the Design of Social Futures. Ed. Bill Cope and Mary Kalantzis. London and New York: Routledge, 2000: 182-202.

--------- . Literacy in the New Media Age. London and New York: Routledge, 2003.

Kress, Gunther, Carey Jewitt, John Ogborn and Charalampos Tsatsarelis. Multimodal Teaching and Learning: The Rhetorics of the Science Classroom. London: Continuum, 2001.

Kress, Gunther and Van Leeuwen, Theo. Reading Images: The Grammar of Visual Design. London: Routledge, 1996.

Multimodal Discourse: The Modes and Media of Contemporary Communication. London: Arnold, 2001.

New London Group. 'A Pedagogy of Multiliteracies: Designing Social Futures'. Harvard Educational Review 66.1 (Spring1996): 6092.

Pahl, Kate. 'Children's Text-making at Home: Transforming Meaning across Modes'. Multimodal Literacy. Ed. Carey Jewitt and Gunther Kress. New York: Peter Lang Publishing, 2003: 139-154.

Schutz, Alfred. Reflections on the Problem of Relevance. Ed. Richard Zaner. New Haven and London: Yale University Press, 1970.

Stein, Pippa. 'Rethinking Resources: Multimodal Pedagogies in the ESL Classroom'. TESOL Quarterly 34.2 (2000): 333-336. 
'Rights, Representation and Resources: Multimodal Communication in South African Classrooms'. Unpublished PhD thesis. Institute of Education, University of London, 2003.

Thesen, Lucia. 'Modes, Literacies and Power: A University Case Study'. Language and Education 14.2 and 3 (2001): 132-145.

Wulf, William. 'Some Thoughts on Engineering as a Humanistic Discipline'. International Journal of Engineering Education 20.3 (2004): 3 13-3 14. 